\title{
APLICAÇÃO DO MODELO CERES-MAIZE NA ANÁLISE DE ESTRATÉGIAS DE IRRIGAÇÃO PARA MILHO "SAFRINHA" EM LONDRINA-PR ${ }^{1}$
}

\author{
CÉLIO O. CARDOSO ${ }^{2}$, ROGÉRIO T. DE FARIA ${ }^{3}$, MARCOS V. FOLEGATTI ${ }^{4}$
}

\begin{abstract}
RESUMO: Usando-se a capacidade do modelo CERES-maize de simular o crescimento do milho sob várias condições de ambiente e manejo, foram analisadas estratégias de irrigação para o milho "safrinha", em diferentes épocas de semeadura, em Londrina-PR. Os tratamentos simulados constituíram-se no cultivo da cultivar de milho XL-520, em 12 épocas de semeaduras, no período de janeiro a abril, adotando-se cinco critérios para aplicação de irrigação, além de um nível sem irrigação e outro de produção potencial. Para as simulações, foram utilizados os dados meteorológicos da série histórica disponível para o local, características do solo predominante da região e manejo, seguindo as recomendações técnicas regionais para o cultivo. Os resultados revelaram que a irrigação foi uma alternativa viável, pois elevou notoriamente o rendimento em todas as épocas de semeadura, variando, em média, entre 5.800 e $8.000 \mathrm{~kg} \mathrm{ha}^{-1}$, reduzindo os riscos de estabelecimento e frustração de safra para essa cultivar. Em todos os níveis, a irrigação resultou em rendimentos mais estáveis ao longo de todo o período de análise, em relação à condição sem irrigação, exceto no primeiro decêndio de janeiro.
\end{abstract}

PALAVRAS-CHAVE: simulação, modelo matemático, viabilidade.

\section{ANALYSIS OF IRRIGATION STRATEGIES FOR CORN OUT SEASON IN LONDRINA WITH THE CERES-maize MODEL}

SUMMARY: Irrigation strategies for the "out season" corn were analyzed in different sowing times in Londrina - PR using the CERES-maize capacity to simulate the growth of the corn under a range of atmosphere and management conditions. The simulate treatments were constituted of the corn hybrid XL-520, in 12 sowing times, in the period from January to May, being adopted five criteria for irrigation application, besides a level without irrigation and another of potential production. For simulations it has been used the meteorological data of the available historical series ( 24 years), the predominant soil characteristics of the place and the management of the regional technical recommendations for corn cultivation. The results revealed that the irrigation was a viable alternative, because it elevated the yield in all sowing times, varying, on average among 5,800 to $8,000 \mathrm{~kg} \mathrm{ha}^{-1}$, and it reduced the establishment risks and crop frustration for this cultivate. In all the levels, the irrigation resulted in better yields along the whole analysis period, related to condition without irrigation, except in the first sowing time of January.

KEYWORDS: simulation, mathematical model, viability.

\section{INTRODUÇÃO}

O milho "safrinha" é uma modalidade distinta da safra normal, desenvolvendo-se sob condições ambientais subótimas, caracterizadas, principalmente, pela menor disponibilidade hídrica e térmica. No Paraná, o milho "safrinha" é uma cultura de risco, alternando anos de boa produção e outros de

\footnotetext{
${ }^{1}$ Extraído da Tese de Doutorado do primeiro autor

${ }^{2}$ Professor Doutor, Departamento de Engenharia Rural, CAV/UDESC. Av. Luiz de Camões, 2090, Lages - SC, 88520-000, (0XX49) 221 2233. E-mail: a2coc@cav.udesc.br

${ }^{3}$ Pesquisador PhD, IAPAR, Londrina - PR.

${ }^{4}$ Professor Associado, Departamento de Engenharia Rural, ESALQ/USP, Piracicaba - SP.

Recebido pelo Conselho Editorial em: 22-2-2002

Aprovado pelo Conselho Editorial em: 30-7-2003
} 
quebra, sendo incerto o nível de produtividade a ser obtido. Por tratar-se de uma atividade de alto risco, torna-se imperativa a definição de estratégias que visem a um planejamento adequado com menores riscos, mediante a minimização de custos e a otimização de rendimentos dessa cultura. Segundo DIAS et al. (1997), o rendimento do milho "safrinha" depende da época de semeadura, ocorrendo intenso decréscimo de rendimento e maior risco de perda quanto mais tardio for o plantio, devido a geadas e deficiência hídrica.

Em Londrina - PR, freqüentemente, o período de exploração de milho "safrinha" é caracterizado por uma redução gradativa da precipitação e aumento da probabilidade de ocorrência de geadas. Nessas condições, relatou GOMES (1995), o sucesso da safra depende da combinação entre a época de semeadura e o ciclo da cultivar.

Devido ao alto risco desse processo, a maioria dos agricultores que cultivam o milho "safrinha", usa ainda medidas tecnológicas de baixo custo, caracterizando sua aversão ao risco, acarretando baixas produtividades. Além disso, existem poucas informações sobre práticas ideais dessa modalidade de cultivo, o que dificulta sua aceitação por parte dos agricultores. Informações adequadas certamente irão contribuir para a obtenção de maiores produtividades e decréscimos de riscos e prejuízos para essa modalidade de cultivo. A obtenção dessas informações demanda um dispendioso tempo de ensaios e medições morosas e onerosas no campo, que devem ser repetidas ao longo de vários anos, além da limitada aplicabilidade de seus resultados, que só poderão ser utilizados a longo prazo, constituindo-se, atualmente, num processo inviável e ineficiente para executar análises de longo período.

Nesse sentido, os modelos de simulação tornam-se uma ferramenta indispensável para a obtenção de informações dessa natureza, a curto prazo e com baixo custo, pois a necessidade de dados e medidas diretas no campo pode ser reduzida e complementada com informações meteorológicas facilmente disponíveis, que são usadas nas simulações, considerando práticas de manejo específicas necessárias à avaliação da potencialidade de produção da cultura em questão. Atualmente, encontramse disponíveis na literatura alguns modelos para a simulação de crescimento de diversas culturas de importância econômica, cuja eficiência já foi comprovada em várias situações.

Dentre os modelos de simulação, destacam-se os modelos CERES para simulações de crescimento de gramíneas, sendo denominado CERES-maize o que se destina à cultura do milho. A grande importância desses modelos na tomada de decisão está na sua capacidade em permitir ao tomador de decisão a análise de muitas práticas de manejo diferentes, simulando a produção, uso dos recursos e o risco associado ao manejo analisado. Embora os modelos possam ser aplicados amplamente, os maiores benefícios da aplicação desses são alcançados em condições de sistemas agrícolas não tradicionais, como é o caso do milho "safrinha" no Paraná.

Este trabalho teve como objetivos identificar estratégias de manejo da irrigação para o milho "safrinha" em diferentes épocas de semeadura e analisar a viabilidade da irrigação para o milho "safrinha" em Londrina - Paraná.

\section{MATERIAL E MÉTODOS}

As análises das estratégias de manejo de irrigação foram realizadas a partir das simulações utilizando o modelo CERES (Crop-Environment Resource Synthesis) - maize (JONES \& KINIRY, 1986), que é um modelo determinístico, com intervalo de cálculo diário, concebido para quantificar os efeitos independentes e interativos do genótipo, clima, atributos do solo e práticas de manejo do cultivo no crescimento e produção de uma cultivar específica de milho no campo, assim como o balanço hídrico do solo e a dinâmica do nitrogênio durante o ciclo da cultura.

Os dados de entrada do meio físico requeridos pelo CERES-maize podem ser facilmente obtidos, incluindo informações diárias de clima (radiação solar, temperaturas máxima e mínima, e chuva), 
dados de caracterização do solo e condições iniciais de umidade e teor de nitrogênio no solo. Os dados de entrada de manejo requeridos incluem data e profundidade de plantio, população, variedade da cultura, aplicações de fertilizantes e de irrigação. Uma descrição mais detalhada do funcionamento desse modelo é apresentada por JONES \& KINIRY (1986), RITCHIE et al. (1998) e CARDOSO (2001).

Os tratamentos simulados consistiram no cultivo do híbrido de milho XL-520, em 12 épocas de semeadura, no período de janeiro a abril, adotando-se cinco critérios para aplicação de irrigação, além de um nível sem irrigação e outro de produção potencial. As simulações foram realizadas para Londrina (latitude: $23^{\circ} 27^{\prime} \mathrm{S}$; longitude: $51^{\circ} 57^{\prime} \mathrm{W}$; altitude: $585 \mathrm{~m}$ ), cujo clima é classificado como subtropical úmido, caracterizado por verão quente e inverno fresco, com baixa precipitação e geadas ocasionais de junho a agosto. Os dados meteorológicos foram obtidos junto ao IAPAR, de uma série histórica de 24 anos de registros diários de precipitação, temperaturas máxima e mínima do ar, e duração de brilho solar. O solo característico da região foi classificado como Latossolo Roxo (Typic Haplorthox), caracterizado por conteúdos de argila de 40 a $60 \%$, perfis profundos, nível de água freática ausente ou profundo e baixo conteúdo de matéria orgânica (menor que 3\%), cujas características são fornecidas por FARIA et al. (1997).

Os coeficientes genéticos do híbrido de milho, cultivar XL-520, do tipo precoce foram obtidos de um estudo de calibração, segundo LIMA (1995).

As condições de manejo para o milho "safrinha" seguiram as recomendações técnicas sugeridas para a região. Considerou-se o espaçamento de $0,9 \mathrm{~m}$ entre linhas, com 6 plantas $\mathrm{m}^{-2}$, e aplicação de nitrogênio nas doses de $20 \mathrm{~kg} \mathrm{ha}^{-1}$ na semeadura e $50 \mathrm{~kg} \mathrm{ha}^{-1}$ aos 45 dias após a semeadura (adubação de cobertura).

As simulações foram processadas considerando-se três cenários: produção potencial, sem irrigação e sob irrigação. Para as simulações no cenário de produção potencial, o modelo assume que água e nitrogênio não são limitantes, ou seja, a produção potencial fica condicionada principalmente aos elementos climáticos, tais como radiação solar e temperatura. Para o cenário sem irrigação, as simulações em todos os anos da série histórica começaram aos 60 dias antes da data estabelecida para cada época de semeadura, para que o modelo estimasse as condições de umidade do solo para a semeadura. As condições iniciais de umidade do solo, no início de cada simulação, foram consideradas em $50 \%$ da capacidade de água disponível em todas as camadas do perfil do solo. Para possibilitar as comparações entre as simulações, assumiu-se, para os cenários de produção potencial e sob irrigação, que as semeaduras ocorriam nas mesmas datas de semeadura obtidas no cenário sem irrigação, ou seja, nas mesmas datas em que as condições necessárias para o estabelecimento da cultura estavam disponíveis em cada decêndio. Nos decêndios em que ocorreram falhas no estabelecimento da cultura no cenário sem irrigação, decorrentes principalmente da escassez de chuva, a semeadura no cenário sob irrigação foi realizada no último dia do decêndio, assumindo-se que a umidade fosse igual a 100\% de água disponível no solo, proporcionado pela irrigação efetuada antes da semeadura.

As estratégias de irrigação consistiram em teores da água no solo (níveis críticos de água no solo) para iniciar a irrigação entre 10 e $90 \%$ da água disponível (AD) no solo, em intervalos de $20 \%$, totalizando cinco níveis, na profundidade de $30 \mathrm{~cm}$, além de um nível sem irrigação, que constituíram os tratamentos nas simulações, para cada data de semeadura. Nos tratamentos com irrigação, considerou-se que a água foi aplicada de forma instantânea e uniforme por um sistema de pivôcentral e que a água de irrigação não representava um recurso limitante. Essas estratégias foram analisadas a partir dos seguintes critérios: máximo rendimento físico, lucro máximo e minimização dos riscos econômicos para o agricultor, analisados pela dominância estocástica das funções de probabilidade. Essa análise baseia-se na comparação entre as distribuições cumulativas de probabilidade dos rendimentos ou retornos, que estão associadas às diferentes alternativas em questão (estratégias 
específicas). Considera-se a distribuição total dos resultados, ao invés de apenas os dois primeiros momentos da distribuição. Assim, a alternativa preferida é aquela que possibilita maiores retornos e oferece menor probabilidade de o nível de retorno cair abaixo de um determinado valor. No caso em que as distribuições cumulativas das alternativas se cruzam, não se pode decidir imediatamente. Isso significa que cada uma delas apresenta melhores resultados até um determinado nível de retorno, a partir do qual outra alternativa passa a ser mais interessante. Nesse caso, recorre-se a maiores graus de dominância estocástica, para que se possa proceder a escolha. É necessário que a alternativa dominante tenha retorno e limite inferior da distribuição cumulativa das probabilidades mais elevadas que as alternativas dominadas. Isso nem sempre ocorre e constitui-se uma limitação do método (PACHECO, 1985; MOUTINHO, 1977).

Para a análise econômica, os dados referentes a preços de insumos e do produto foram obtidos nas publicações da Companhia Nacional de Abastecimento (CONAB, 2000) e da Secretaria de Agricultura do Paraná, além de outras publicações disponíveis na literatura. A partir desses dados, procedeu-se à análise econômica, assumindo um preço médio fixo do produto.

Os valores de renda bruta em cada estratégia foram obtidos multiplicando-se a produtividade pelo preço unitário do produto. O preço unitário apresentou os seguintes valores no período de 1993 a 1999 (NICOLETTI, 1997; AGRIANUAL, 1999; CONAB, 2000): valor médio igual a $\mathrm{R} \$ 137,00 \mathrm{t}^{-1}$; valor mínimo igual a $\mathrm{R} \$ 109,00 \mathrm{t}^{-1}$, e valor máximo igual a $\mathrm{R} \$ 186,00 \mathrm{t}^{-1}$; esses valores são correspondentes a dezembro de 1999, após serem deflacionados com o índice geral de preços (IGP) da Fundação Getúlio Vargas. O custo básico de produção (CBP) foi considerado como um valor constante, independentemente do aumento da produção decorrente da estratégia implementada. Segundo AGRIANUAL (1999), o valor médio de custo básico de produção para o milho "safrinha" é igual a $\mathrm{R} \$ 355,00 \mathrm{ha}^{-1}$. Para o custo variável da irrigação, considerou-se uma variação linear obtida pelo produto da lâmina de irrigação e um valor unitário constante $\left(\mathrm{R} \$ \mathrm{~mm}^{-1}\right)$, acrescido pelos custos operacionais para cada aplicação da irrigação. Adotou-se o valor de $\mathrm{R} \$ 0,50 \mathrm{~mm}^{-1}$, que foi obtido de uma média de vários projetos de irrigação com pivô-central (FRIZZONE et al., 1994). Os custos fixos da irrigação incluíram os valores da depreciação para uma vida útil de 10 anos e juros de capital de $12 \%$ ao ano, totalizando um valor de $\mathrm{R} \$ 145,00 \mathrm{ha}^{-1}$ (FRIZZONE et al., 1994), assumido ser esse o valor total dos custos médios para áreas irrigadas com pivô-central.

As médias e desvios das rendas líquidas, bem como suas funções de probabilidade acumulada, foram então calculadas e usadas para resumir e comparar as estratégias. As funções de probabilidade acumulada foram obtidas ordenando-se a série dos valores da variável em estudo em ordem crescente e relacionando-os com as probabilidades cumulativas em intervalos eqüidistantes.

A comparação dos contrastes entre os tratamentos em cada decêndio foi feita com o teste Tukey, utilizando para efetuar a análise de variância o aplicativo SW NTIA - EMBRAPA-CNTIA (1997) v.4.2.2, considerando um nível de significância de $5 \%$ de probabilidade.

\section{RESULTADOS E DISCUSSÃO}

Observa-se, na Figura 1, que os valores médios de rendimento para os tratamentos com irrigação foram próximos em todas as épocas de semeadura, variando entre 5.800 a $8.000 \mathrm{~kg} \mathrm{ha}^{-1}$, e o tratamento de iniciar a irrigação com $90 \%$ de água disponível no solo apresentou, em média, resultados de rendimento um pouco inferiores aos demais. Esse fato é justificado por ocorrer maior perda de nitrogênio pela lixiviação, devido à maior freqüência de irrigação com essa estratégia e ocorrência de chuvas logo após as mesmas, não possibilitando que o solo pudesse reter toda a água recebida. Nessas condições, é gerado maior volume de escoamento superficial e de percolação profunda, lixiviando mais intensamente o nitrogênio. Verificaram-se maiores estresses de nitrogênio quando a cultura foi irrigada com maior freqüência e maiores estresses hídricos devido à menor velocidade de absorção de 
água no tratamento de iniciar a irrigação com $10 \%$ de $\mathrm{AD}$ no solo. O tratamento de iniciar a irrigação a $50 \%$ de água disponível no solo foi o que proporcionou os maiores rendimentos médios na maioria das épocas de semeadura. $\mathrm{O}$ incremento nos rendimentos simulados devido ao efeito da irrigação tendeu a ser maior à medida que se atrasou a semeadura, devido à menor disponibilidade de água no solo decorrente de menores chuvas nesta época, resultando em maior déficit hídrico no cenário sem irrigação, que ocorre na média dos anos no período de outono-inverno. A irrigação proporcionou aumentos notáveis nos rendimentos médios em todas as épocas de semeadura, apresentando os maiores acréscimos a partir de abril, quando comparados com a simulação sem irrigação. Considerando-se as falhas no estabelecimento como sendo rendimento nulo para o cálculo do rendimento médio do cenário sem irrigação, a diferença entre rendimentos nos cenários fica ainda mais evidente. Os menores rendimentos médios nos tratamentos com irrigação ocorreram nas semeaduras do terceiro decêndio de março, ficando em torno de $5.800 \mathrm{~kg} \mathrm{ha}^{-1}$, e os maiores rendimentos médios no primeiro decêndio de fevereiro, em torno de $8.000 \mathrm{~kg} \mathrm{ha}^{-1}$.

$\mathrm{Na}$ análise de variância (Tabela 1), verificou-se que os rendimentos médios dos tratamentos com irrigação foram bastante semelhantes em cada decêndio, não apresentando diferenças significativas no nível de $5 \%(\alpha=0,05)$ entre seus valores. Nessa análise, também foi verificado que, em relação ao cenário sem irrigação, apenas na semeadura do primeiro decêndio de janeiro, o acréscimo de rendimento devido à irrigação não apresentou diferença significativa a $5 \%$ de probabilidade e, quanto mais tardia a semeadura, maior a diferença nos rendimentos médios entre os cenários.

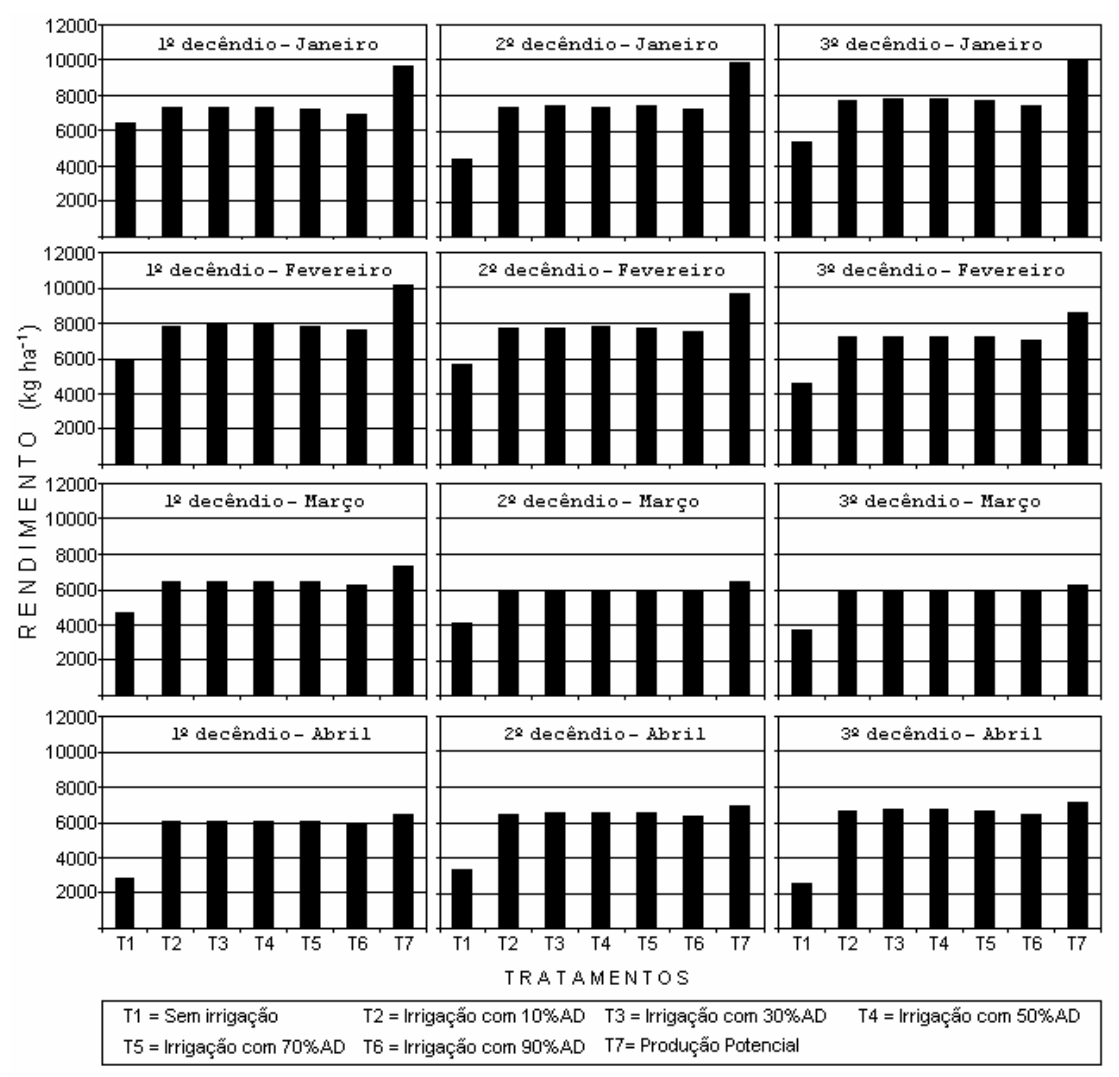

FIGURA 1. Rendimentos médios dos cenários de produção potencial, sem irrigação e com irrigação, em diferentes níveis críticos de umidade do solo $(10 \%, 30 \%, 50 \%, 70 \%$ e $90 \%$ de AD), nas diferentes épocas de semeadura do milho "safrinha". 
Quando foram comparados os rendimentos dos tratamentos de irrigação com os rendimentos potenciais, verificou-se que existem diferenças significativas $(\alpha=0,05)$ apenas nas semeaduras dos meses de janeiro e fevereiro. Essas diferenças podem ser atribuídas aos estresses decorrentes da deficiência de nitrogênio, que foi influenciada pela maior lixiviação desse nutriente, devido à maior ocorrência de chuvas nesse período de exploração do cultivo do milho "safrinha". Adequadas condições hídricas no solo, na média dos anos, possibilitam maior acúmulo de fotoassimilados, resultando em altos rendimentos. Então, tendo sido supridas as necessidades hídricas da cultura pela irrigação, os decréscimos simulados em relação à produção potencial foram atribuídos a deficiências de nitrogênio. $O$ modelo considera que a maior limitação de nitrogênio não permite que a cultura aproveite melhor a água ministrada via irrigação. Mesmo assim, os acréscimos nos rendimentos foram significantes em relação ao cenário sem irrigação, exceto no primeiro decêndio de janeiro.

TABELA 1. Análise de variância dos rendimentos médios nos cenários de produção potencial, sem irrigação e com irrigação, em diferentes níveis críticos de umidade do solo $(10 ; 30 ; 50$; 70 e $90 \%$ de AD), nas diferentes épocas de semeadura do milho "safrinha" em Londrina PR.

\begin{tabular}{|c|c|c|c|c|c|c|c|c|}
\hline \multicolumn{2}{|c|}{ Período } & \multicolumn{7}{|c|}{ Tratamentos } \\
\hline Mês & Decêndio & T 1 & T 2 & T 3 & T 4 & T 5 & Т 6 & T 7 \\
\hline \multirow{3}{*}{ janeiro } & $1^{\underline{o}}$ & $6.449 \mathrm{~b}$ & $7.342 \mathrm{~b}$ & $7.357 \mathrm{~b}$ & $7.341 \mathrm{~b}$ & $7.239 \mathrm{~b}$ & $6.972 \mathrm{~b}$ & $9.675 \mathrm{a}$ \\
\hline & $2^{-}$ & $4.357 \mathrm{c}$ & $7.278 \mathrm{~b}$ & $7.366 \mathrm{~b}$ & $7.353 \mathrm{~b}$ & $7.413 \mathrm{~b}$ & $7.173 b$ & $9.872 \mathrm{a}$ \\
\hline & $3^{-}$ & $5.356 \mathrm{c}$ & $7.666 \mathrm{~b}$ & $7.755 \mathrm{~b}$ & $7.766 \mathrm{~b}$ & $7.684 \mathrm{~b}$ & $7.434 b$ & $10.034 \mathrm{a}$ \\
\hline \multirow{3}{*}{ fevereiro } & $1^{\mathrm{O}}$ & $5.940 \mathrm{c}$ & $7.875 \mathrm{~b}$ & $7.916 \mathrm{~b}$ & $7.956 \mathrm{~b}$ & $7.878 \mathrm{~b}$ & $7.683 \mathrm{~b}$ & $10.150 \mathrm{a}$ \\
\hline & $2^{\mathrm{o}}$ & $5.620 \mathrm{c}$ & $7.710 \mathrm{~b}$ & $7.720 \mathrm{~b}$ & $7.755 \mathrm{~b}$ & $7.711 \mathrm{~b}$ & $7.525 \mathrm{~b}$ & $9.630 \mathrm{a}$ \\
\hline & $3^{0}$ & $4.620 \mathrm{c}$ & $7.165 \mathrm{~b}$ & $7.235 \mathrm{~b}$ & $7.234 \mathrm{~b}$ & $7.189 \mathrm{~b}$ & $7.045 \mathrm{~b}$ & $8.618 \mathrm{a}$ \\
\hline \multirow{3}{*}{ março } & $1^{0}$ & $4.718 \mathrm{~b}$ & $6.448 \mathrm{a}$ & $6.481 \mathrm{a}$ & $6.496 \mathrm{a}$ & $6.494 \mathrm{a}$ & $6.315 \mathrm{a}$ & $7.366 \mathrm{a}$ \\
\hline & $2^{\underline{o}}$ & $4.127 b$ & $5.928 \mathrm{a}$ & $5.947 \mathrm{a}$ & $5.971 \mathrm{a}$ & $5.954 \mathrm{a}$ & $5.867 \mathrm{a}$ & $6.471 \mathrm{a}$ \\
\hline & $3^{\mathrm{o}}$ & $3.745 \mathrm{~b}$ & $5.880 \mathrm{a}$ & $5.889 \mathrm{a}$ & $5.927 \mathrm{a}$ & $5.903 \mathrm{a}$ & $5.819 \mathrm{a}$ & $6.234 \mathrm{a}$ \\
\hline \multirow{3}{*}{ abril } & $1^{\mathrm{O}}$ & $2.797 \mathrm{~b}$ & $6.082 \mathrm{a}$ & $6.128 \mathrm{a}$ & $6.144 \mathrm{a}$ & $6.108 \mathrm{a}$ & $5.970 \mathrm{a}$ & $6.464 \mathrm{a}$ \\
\hline & $2^{\underline{o}}$ & $3.315 \mathrm{~b}$ & $6.476 \mathrm{a}$ & $6.551 \mathrm{a}$ & $6.550 \mathrm{a}$ & $6.490 \mathrm{a}$ & $6.338 \mathrm{a}$ & $6.963 \mathrm{a}$ \\
\hline & $3^{-0}$ & $2.549 \mathrm{~b}$ & $6.626 \mathrm{a}$ & $6.684 \mathrm{a}$ & $6.718 \mathrm{a}$ & $6.666 \mathrm{a}$ & $6.456 \mathrm{a}$ & $7.098 \mathrm{a}$ \\
\hline
\end{tabular}

T 1 - sem irrigação; T 2 - irrigação com $10 \%$ de $\mathrm{AD} ; \mathrm{T} 3$ - irrigação com $30 \%$ de $\mathrm{AD}$; T 4 - irrigação com $50 \%$ de $\mathrm{AD}$; T 5 - irrigação com $70 \%$ de $\mathrm{AD}$; $\mathrm{T} 6$ - irrigação com $90 \%$ de $\mathrm{AD} ; \mathrm{T} 7$ - produção potencial.

Obs.: Em cada decêndio, médias com letras iguais não diferem significativamente, a 5\% de probabilidade (Teste de Tukey).

Em todos os níveis de irrigação, os rendimentos foram mais estáveis ao longo do período de exploração do milho "safrinha" em comparação, o que pode ser melhor verificado com as funções de probabilidade acumulada de cada decêndio (CARDOSO, 2001). Na maioria das épocas de semeadura, a irrigação apresentou uma dominância estocástica de primeiro grau em relação ao tratamento sem irrigação (nove decêndios), e dominância de segundo grau nos demais. O tratamento de iniciar a irrigação com $50 \%$ de água disponível (AD) no solo apresentou dominância estocástica de segundo grau na maioria das épocas de semeadura analisadas, exceto no primeiro e segundo decêndios de janeiro, onde a dominância foi do tratamento de iniciar a irrigação com 30\% e 70\% de AD no solo, respectivamente, porém sem apresentar diferença significativa $(\alpha=0,05)$ em relação aos demais tratamentos. O tratamento de irrigação que, em geral, foi mais dominado, correspondeu ao nível de iniciar a irrigação a $90 \%$ de $\mathrm{AD}$ no solo, devido a maiores deficiências de nitrogênio. A maior contribuição da irrigação para os rendimentos ocorreu nas semeaduras do terceiro decêndio de abril, e a menor contribuição no primeiro decêndio de janeiro. Observou-se que, com a irrigação, os riscos de frustrações de rendimento foram minimizados. 
Devido à grande variabilidade climática com que os cultivos se defrontam quando semeados em épocas distintas nessa região, decorrente principalmente das chuvas e demanda evaporativa da atmosfera, as respostas à irrigação também foram diferenciadas, principalmente no que diz respeito à quantidade de água e números de aplicações de irrigação. Assim, foi analisada a viabilidade econômica da irrigação para cada época de semeadura aqui considerada.

Analisou-se, então, a viabilidade econômica da implementação da irrigação dessa cultivar de milho no período da "safrinha", em Londrina - PR. Na Figura 2, observa-se que os maiores resultados médios das receitas líquidas obtidos para o milho "safrinha" (cultivar XL-520), para o cenário de manejo da irrigação, nas 12 épocas de semeaduras, foram obtidos na semeadura do primeiro decêndio de fevereiro, e os menores na semeadura do terceiro decêndio de março, em todos os níveis de irrigação analisados. O tratamento de iniciar a irrigação em $90 \%$ de $\mathrm{AD}$ no solo é o que resulta em menores receitas líquidas, devido ao fato de necessitar de um maior volume de água, resultando em aumentos consideráveis nos custos de produção. As maiores receitas líquidas no cenário de irrigação foram obtidas no tratamento de iniciar a irrigação em $10 \%$ de $\mathrm{AD}$ no solo, devido à menor freqüência de irrigação, necessitando de menores quantidades de água, minimizando, dessa forma, os custos totais de produção.

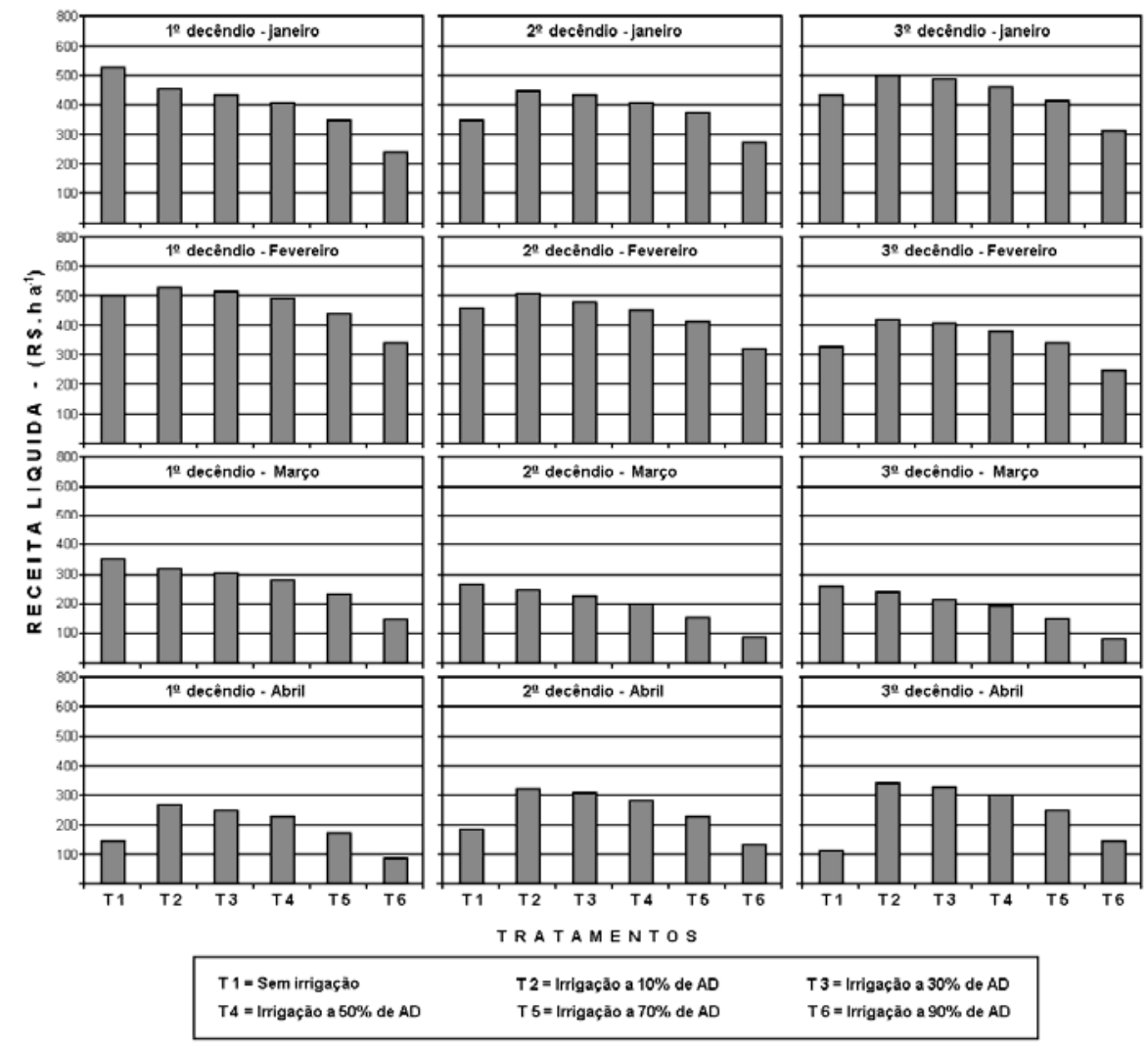

FIGURA 2. Receitas líquidas médias do milho "safrinha" para os cenários sem irrigação e com irrigação (\% de AD), semeado no período de janeiro a abril, em 24 anos de simulações.

Notou-se que, com o aumento da freqüência de irrigação (aumento do nível de AD para iniciar a irrigação), ou seja, com o aumento da quantidade de água aplicada via irrigação, as receitas líquidas foram decrescentes, devido ao aumento dos custos variáveis da irrigação, pois esses foram considerados como sendo proporcionais ao volume de água aplicado à cultura ( $\left.\mathrm{R} \$ \mathrm{~m}^{-3} \mathrm{ha}^{-1}\right)$. Ao confrontar as receitas líquidas entre os cenários com e sem irrigação, verificou-se que o tratamento 
sem irrigação proporcionou resultados médios maiores para a semeadura no primeiro decêndio de janeiro e nos três decêndios do mês de março, e o tratamento de iniciar a irrigação com 10\% de AD no solo foi superior nas semeaduras dos demais decêndios analisados. O tratamento de irrigar com 90\% de AD no solo propiciou receitas líquidas médias inferiores ao tratamento sem irrigação na maioria das épocas de semeaduras, exceto no terceiro decêndio de abril.

As funções de probabilidade acumulada das receitas líquidas para a cultivar XL-520, semeada nos 12 decêndios de janeiro a abril em Londrina, obtidas a partir das simulações com o modelo CERES-maize, para a comparação entre as estratégias de irrigação e sem irrigação, mostraram que o tratamento sem irrigação foi dominante em segunda ordem na semeadura do primeiro decêndio de janeiro e nas semeaduras correspondentes ao mês de março, principalmente devido aos grandes prejuízos (receitas líquidas negativas) que ocorreram com probabilidade ao redor de 10 a $15 \%$. Nas demais épocas de semeadura, a irrigação iniciando a $10 \%$ de $\mathrm{AD}$ no solo foi dominante, e a irrigação começando a $90 \%$ de AD foi sempre dominada em todas as épocas de semeadura. Isso pode ser atribuído ao aumento dos custos à medida que um volume maior de água se torna necessário e por ser o tratamento que resulta em menores rendimentos decorrente de maiores deficiências de nitrogênio. Na semeadura do terceiro decêndio de abril, foram obtidos os maiores incrementos nos valores médios de receita líquida com o uso da irrigação. Analisadas as curvas de probabilidades acumuladas, apresentadas por CARDOSO (2001), é possível constatar que a prática da irrigação possibilita maior estabilidade nas receitas líquidas em todos os decêndios com menores riscos de prejuízos na maioria dos decêndios analisados.

\section{CONCLUSÕES}

A irrigação elevou os níveis de rendimento em todas as épocas de semeadura, variando em média entre 5.800 a $8.000 \mathrm{~kg} \mathrm{ha}^{-1}$, e reduziu os riscos de estabelecimento da cultura.

Em todos os níveis considerados, a irrigação propiciou rendimentos mais estáveis ao longo de todo o período de análise, apresentando dominância de primeiro e segundo graus em relação à condição sem irrigação, exceto no primeiro decêndio de janeiro.

O incremento nos rendimentos simulados devido ao efeito da irrigação foi maior em abril, devido à menor ocorrência de chuvas nessa época.

Iniciar a irrigação a $50 \%$ de $\mathrm{AD}$ no solo proporcionou os maiores rendimentos médios na maioria das épocas de semeadura, e a irrigação iniciando com $90 \%$ de $\mathrm{AD}$ no solo apresentou os menores rendimentos médios devido à maior lixiviação de $\mathrm{N}$ no solo.

A irrigação resultou em maiores valores médios de receita líquida para a maioria das épocas de semeadura e sempre se associou a menores riscos de prejuízos.

\section{REFERÊNCIAS BIBLIOGRÁFICAS}

AGRIANUAL 1999: anuário da agricultura brasileira. São Paulo: FNP Consultoria e Comércio, 2000. $521 \mathrm{p}$.

Companhia Nacional de Abastecimento (CONAB). Levantamento, jul/00, 2000.

<www.conab.gov.br/publicações/indicadores.> Acesso em: 15-5-2000.

CARDOSO, C.O. Análise de riscos climáticos e estratégias de irrigação para o milho "safrinha" no Paraná, mediante modelos de simulação. 2001. 114 f. Tese (Doutorado) - Escola Superior de Agricultura “Luiz de Queiroz”, Universidade de São Paulo, Piracicaba, 2001.

BERNARDO, D.J.; WHITTLESEY, N.K.; SAXTON, K.E.; BASSET, D.L. Irrigation optimization under limited water supply. Transactions of the ASAE, St. Joseph, v.31, p.712-19, 1988. 
DIAS, H.S.; BALHESTERO, J.A.V.; VETULLO, D.; GUTIERREZ, L.S.D. Época da semeadura do milho "safrinha" em função da colheita da soja. In: SEMINÁRIO SOBRE A CULTURA DO MILHO "SAFRINHA", 4., 1997, Londrina. Resumos... p.57-60.

FARIA, R.T.; FOLEGATTI, M.V.; FRIZZONE, J.A.; SAAD, A.M. Determination of a long-term optimal irrigation strategy for dry beans in Paraná State, Brazil. Sciencia Agricola, Piracicaba, v.54, (número especial), p.155-64, 1997.

FRIZZONE, J.A.; BOTREL, T.A.; FREITAS, H.A.C. Análise comparativa dos custos de irrigação por pivô-central em cultura de feijão, utilizando energia elétrica e óleo diesel. Engenharia Rural, Piracicaba, v.5, n.1, p.24-53, 1994.

GOMES, J. Estudos de risco para o milho "safrinha". In: SEMINÁRIO SOBRE A CULTURA DO MILHO “SAFRINHA”, 3., 1995, Assis. Anais... p.111-13.

IBSNAT (Project). Documentation for IBSNAT crop model input and output files. Version 1.1, for the Decision Support System for Agrotechnology Transfer (DSSAT V2.1). Dep. of Agronomy and Soil Sci., College of Tropical Agric. And Human Resources, Univ. of Hawaii, 1990. (IBSNAT Tech. Rep.5)

JONES, C.A.; KINIRY, J.R. CERES-maize: A simulation model of maize growth and development. Texas: A \& M Univ. Press., College Station, 1986. 194 p.

LIMA, M.G. Calibração e validação do modelo CERES-maize em condições tropicais do Brasil. 1995. 119 f. Tese (Doutorado) - Escola Superior de Agricultura "Luiz de Queiroz", Universidade de São Paulo, Piracicaba, 1995.

MOUTINHO, D.A. Escolha de nova tecnologia sob condições de risco: o caso do feijão de corda em Quixadá. 1977. 118 f. Dissertação (Mestrado em Fitotecnia) - Universidade Federal do Ceará, Fortaleza, 1977.

NICOLETTI, A. Mercado do milho. In: SEMINÁRIO SOBRE A CULTURA DO MILHO "SAFRINHA", 4., 1997, Londrina. Resumos... p.1-10.

PACHECO, J.A.C. Modelos de decisão na análise econômica de experimentos agrícolas. 1985. $111 \mathrm{f}$. Dissertação (Mestrado) - Escola Superior de Agricultura "Luiz de Queiroz”, Universidade de São Paulo, Piracicaba, 1985.

RITCHE, J.T.; SINGH, U.; GODWIN, D.C.; BOWEN, W.T. Cereal growth, development and yield. In: TSUJI, G. Y.; HOOGENBOOM, G.; THORTON, P. K. (Ed.) Understanding options for agricultural production. Dordrecht: Kluwer Academic Publishers, 1998. p.79-98. 